\title{
УДК $81+81.37$
}

\section{ДИНАМИЧЕСКИЕ ПРОЦЕССЫ В СЕМАНТИЧЕСКОМ ПОЛЕ «СМЕХ»}

\author{
(НА МАТЕРИАЛЕ РУССКОГО ЯЗЫКА)
}

\author{
С. А. Попова (Новосибирск, Россия)
}

\begin{abstract}
В статье описаны динамические прочессы, происходящие в семантическом поле "Смех». Отмечается, что в него входят лексико-семантические группы (глаголов, существительных, прилагательных, наречий, слов категории состояния и междометий). Подчеркивается, что активные процессы в данном семантическом поле в первую очередь касаются изменения лексико-семантических групп глаголов (с примыкаюшими к ним глагольными фразеологизмами) и существительных. Особое внимание уделяется появлению новых лексем и новых значений, а также потере актуальности слов для носителей языка и выходу их из употребления. В заключение делаются выводы, что семантическое поле "Смех» - это самоорганизуюшийся динамический фрагмент лексической системы языка, пребывающий в постоянном движении и развитии. Динамические процессы в семантическом поле "Смех», во-первых, показывают изменения жизни русского сочиума, во-вторых, отражают изменения в русской языковой картине мира: вместе с уходом части лексики уходит определенный пласт смеховой культуры, происходит смена смеховой парадигмы.
\end{abstract}

Ключевые слова: динамические процессы, семантическое поле, лексико-семантическая группа, лексическое значение, сема, компонентный анализ.

Известно, что лексический уровень языка более других подвержен историческим изменениям. Ю. С. Маслов отмечал, что «изменения в фонологической системе и звуковой «материи» языка, в его грамматическом строе трудно заметить на протяжении жизни одного поколения», а «изменения в словарном составе наблюдаются повседневно» [4, с. 271]. «Каждый новый этап в развитии общественной жизни, - писал С. И. Ожегов, - наклады- вал свой отпечаток на словарный состав языка. С каждым новым этапом развития появлялись новые слова и выражения, изменялись значения, выпадали из словарного состава устаревающие слова» [5].

В семантическом поле «Смех» как в лексической макропарадигме языка происходят динамические процессы, связанные с изменением жизни социума, а также с изменением картины мира носителей языка.

Попова Светлана Андреевна - аспирант кафедры современного русского языка, Новосибирский государственный педагогический университет.

E-mail: spspsp@list.ru 
Последнее замечание представляется нам очень важным. Мысль о том, что семантическое поле отражает языковую картину мира, прослеживается в трудах многих ученых: Ю. Н. Караулова, А. А. Уфимцевой, Л. А. Новикова, И. М. Кобозевой и др. Так, по Ю. Н. Караулову, семантическое поле выступает как характеристика «индивидуума, среднего носителя языка, воспринимающего действительность» и как характеристика самой действительности [2, с. 176].

В данной статье представлено исследование динамических процессов, происходящих в семантическом поле «Смех», которое позволит выявить некоторые изменения, характерные для современной русской языковой картины мира.

Семантическое поле «Смех» представляет собой совокупность лексико-семантических групп (глаголов, существительных, прилагательных, наречий, слов категории состояния и междометий), в которую входит около 400 лексических единиц. Активные процессы в данном семантическом поле в первую очередь касаются изменения состава лексико-семантических групп (далее - ЛСГ) глаголов (с примыкающими к ним глагольными фразеологизмами) и существительных и происходят в двух основных направлениях: 1) появление новых лексем и новых значений; 2) перемещение лексических единиц в периферийную зону словаря.

В ЛСГ глаголов и глагольных фразеологизмов со значением действий, совершаемых человеком с целью вызвать смех, наряду с лексическими единицами дурачиться, развлекать, забавлять, чудить, балагурить, шутить (в 1-м значении «весело и забавно говорить, поступать; делать что-нибудь ради забавы»), валять дурака, балаганить, фиглярить и т. д. входит новое слово петросянить, образованное от фамилии известного россий- ского юмориста. Обратимся к примерам из разговорной речи: Дмитрий, хватит петросянить. Уже как-то не смешно; Опять петросянишь. Взросльй человек, а все ерунду говоришь. Как видим из примеров, слово петросянить обросло негативными коннотациями: петросянить - вести себя, подобно юмористу Евгению Петросяну, то есть шутить несмешно, глупо. Качество юмора Е. Петросяна определенной частью современного русскоязычного социума оценивается очень невысоко. В связи с этим в повседневный обиход в той или иной мере входят новые слова и значения: петросянить, петросянство или петросянщцина в значении «несмешной, глупый юмор», а сама фамилия юмориста становится именем нарицательным и употребляется в значении «плохой шутник; человек, который постоянно пытается шутить, но у него получается неудачно». Перечисленные лексемы являются разговорными и, естественно, не закреплены в нормативных словарях.

В семантическое поле «Смех» входят и новые слова, заимствованные из английского языка: смайлик (и смайл) и ЛОЛ. Smile в переводе с английского - «улыбка». Слова смайл и смайлик традиционно обозначали графическое изображение лица улыбающегося (или смеющегося) человека в виде желтого круга с двумя черными точками, представляющими глаза, и черной дугой, символизирующей рот: :). В последнее время слово смайлик используется в качестве общего термина для наименования изображения любой эмоции и эмоционального состояния, причем не только графически, но и знаками препинания, буквами, цифрами, например: :) или :-( выражение грусти, печали, :-С - сильное огорчение, :-0 или O_о - удивление, :-[ смущение и др. Сейчас смайлики широко используются в интернет- и смс-общении, а 
лексема смайлик уже нашла свое отражение в Толковом словаре С. И. Ожегова (далее ТCO) 2013 г.:

Смайлик (сnеu.) - в информатике, в электронной почте: комбинация принятых символов для передачи эмоции отправителя удивления, огорчения, улыбки и т. п. [7].

Слово ЛОЛ (или лол), которое может писаться как на русском, так и английском языке, происходит от английской аббревиации $L O L$ (или $l o l$ ), которая может объясняться тремя способами: 1) laughing out loud «громко, вслух смеясь»; 2) laugh out loud «громко, вслух смеяться»; 3) lots of laughs «много смеха». Лексема лол используется в сетевом общении главным образом для выражения смеха в письменной форме, например: И это, товарищи, Варкрафт 3. А еще Софтклаб считают одним из лучших издателей у нас. И лучшей локализачией. Лол; Лол! Бесит в каких-нибудь сообществах пишут: «У меня рост вот 170, а вес 40 кг. Я такая толстая». Если английское LOL в марте 2011 г. было занесено в Оксфордский словарь английского языка, то заимствованное и оформленное русскими буквами ЛОЛ, возможно, скоро будет занесено в словарь компьютерного сленга.

Расширение семантического поля происходит в основном за счет вхождения в него слов в новом (жаргонном или разговорном) значении. Это такие слова, как, например, прикальвваться, прикол, прикольньй, приколист, приколистка, стебать, стёб, стегать, выстегивать, стегальщик, стегальщчича, угорать, угар, угарный и др.

В пределах семантического поля «Смех» лексемы прикальваться, стегать, cтебать, выстегивать примыкают к глаголам насмехаться, высмеивать, иутить (во 2-м значении «смеяться над кем-то»), дразнить, забавляться, осмеивать, передразни- вать, зубоскалить, издеваться, насмешничать, подтрунивать, подщучивать и т. д., входящим в ЛСГ глаголов и глагольных фразеологизмов со значением действий, характеризующих насмешливое / шутливое отношение к объекту смеха. Слова прикол, стёб наряду со словами насмешка, глумление, издевка и др. входят в ЛСГ существительных наименований типов смеха по характеру отношения к объекту смеха. Приколист, приколистка, стегальщик, стегальщища относятся к ЛСГ существительных - наименований субъектов смеха (например, насмешник, зубоскал, весельчак, юморист и др.). Угарный и прикольный (наряду со словами смешной, забавнылй, потешный, юмористичный, комичныцй, конфузныцй и др.) относятся к ЛСГ прилагательных, характеризующих объекты смеха. Рассмотрим механизм возникновения новых значений слов, позволяющих включать перечисленные лексемы в семантическое поле «Смех».

В ТСО 2010 г. лексема прикол представлена как однозначная:

Прикол (спещ.) - свая, кол, укрепленные в земле (для причала, привязи) [6].

Однако ТСО 2013 г. уже фиксирует изменения в семной и семантической структурах слова и приводит омоним:

Прикол ${ }^{2}$ (npocm.) - в молодежной речи: шутка, розыгрыш [7].

Слово приколоться в ТСО 2013 г. отсутствует, хотя в него уже включены лексемы приколист и прикольный:

Приколист (разг.) - тот, кто склонен к розыгрышам, шуткам, остроумным проделкам, приколам².

Прикольный - в молодежной речи: вызывающий восхищение, необычный, забавный.

Большой толковый словарь русского языка (2009 г.) под ред. С. А. Кузнецова 
(БТС) наиболее последовательно отражает произошедшие языковые изменения: в нем описаны жаргонные значения лексем прикол, прикольньій, приколоться, приколист, прикольщик. БТС рассматривает слово приколоться как многозначное, а слово прикол как лексему, имеющую омоним:

Прикол ${ }^{1}$ - свая, кол, вбитые в землю (для причала лодок, судов, для привязывания животных и т. п.). Привязать на п. лошадь. Лодка на приколе.

Прикол ${ }^{2}$ (жарг.) - шутка, розыгрыш. Выражает восхищение, удивление, восторг и т. п. Вот это прикол! Полный прикол.

Приколоться - 1. Воткнуться кудалибо острием. Кнопка прикололась $\kappa$ полу. 2. (жарг.) Дружески подшутить; посмеяться над кем-либо, чем-либо [1].

Второй лексико-семантический вариант в обоих случаях возникает путем метафорического переноса, основанием для которого служит общая сема 'меткое воздействие чемлибо острым'. Прикол - это острая шутка, а приколоться - пошутить над человеком, сделав ему неприятно, как будто уколов его чемлибо.

Обратим внимание на важность для русского человека концептуального признака «Смех - это оружие» [8, с. 66-67], им можно сделать больно, уколоть, проколоть, уничтожить, победить. В связи с этим рассмотрим, как возникают жаргонные значения слов стебать, стегать и выстегивать. По данным Толкового словаря под ред. Д. Н. Ушакова (2004 г.) и ТСО (2013 г.) значения этих слов совсем не реализуют идею смеха:

Стебать (обл.) - хлестать, стегать, бить плеткой, прутом [11].

Стегать $^{1}$ - хлестать, бить чем-нибудь гнущимся, тонким. Стегать кнутом.
Стегать $^{2}$ - прошивать насквозь положенный между двумя кусками ткани слой ваты. Стегать одеяло [7].

Однако анализ контекстов из Национального корпуса русского языка (далее НКРЯ) показывает наличие у слов переносных значений: Подростки стебаются, передразнивают, посылают матом учителей это во всех школах такое есть (Заместитель министра культуры Пензенской области против показа сериала «Школа» // Комсомольская правда, 2010.01.26); Отчасти мы пародируем «Разрушителей легенд», прикальваемся, стебем их немножко и вносим в проект наш русский колорит (Брагина Лика. Алексей Лихницкий и Роман Юнусов: «Нам надоело быть Лысым и Татьяной» // Труд-7, 2010.04.13).

Стебать или стегать - смеяться над кем-то, высмеивать кого-то. Это метафора, основанием которой служит сема 'меткое воздействие чем-либо острым’; стегать это шить иголкой, стегать - острить, подкалывать, как иголкой. Потенциальная сема 'неприятные ощущения объекта, на которого направлено действие' в значении слов стебать и стегать (со значением «бить, хлестать») становится ядерной в метафорической номинации: человеку, над которым cmeбутся или выстегивают, так же неприятно. Заметим, что БТС (2009 г.) уже фиксирует это переносное значение: стебать (жарг.) насмехаться, иронизировать над кем-либо, чем-либо [1]. В БТС и ТСО (2013 г.) включается лексема стёб со значением «в молодежной речи: насмешка, подтрунивание, ерничанье» [7].

Появилось новое значение у слова угорать - «сильно смеяться, веселиться». Оно не представлено в современных словарях, но выявляется благодаря анализу контекстов из Национального корпуса русского языка: Мне 
Вестник Новосибирского государственного педагогического университета

3(19) $2014 \quad$ www.vestnik.nspu.ru ISSN 2226-3365

сама реклама нравится, а вообще я давно угораю над рекламами средств, где хозяйки в любые места их с собой носят. Я же стираю «Лаской» (Рекламные ролики на TV); Угорать будем или плакать? (Разговоры знакомых // Из материалов Ульяновского университета). В последнем контексте лексема угорать стоит рядом с узуальным антонимом к слову смеяться (плакать), что как раз позволяет понять ее лексическое значение: угорать - сильно смеяться. Данное значение тоже появилось путем метафорического переноса наименования (из 3 значения): угорать - это смеяться, как сумасшедший:

Угореть - 3. перен. Употр. как синоним сойти с ума (о человеке, сделавшем чтонибудь нелепое, несуразное; разг. фам.). Что ты, угорел? [11].

Как видим, расширение границ семантического поля «Смех» происходит за счет появления в языке новых лексем, в том числе иноязычных (например, смайлик и лол), а также новых лексико-семантических вариантов слов русского языка (например, стебать в значении «насмехаться», прикальвваться в значении «шутить, смеяться над кем-либо»). Появление новых слов, а также развитие многозначности слов - два важнейших активных процесса в лексике, за счет которых пополнялся словарный состав русского языка во все времена.

Можно говорить о постоянном развитии и движении семантического поля «Смех». Так, в «Словаре русского языка XI-XVII веков» первый раз зафиксировано употребление слова ржать в переносном значении «смеясь, издавать звуки, подобные конскому ржанию» только в XVII веке [10]. Такая лексема как прыснуть хотя и представлена в данном словаре как многозначная, но не имеет значений, связанных с идеей смеха: 1) с силой выбросить фонтан брызг, капель; 2) фыркнуть.
[9]. Метафорическое значение слова «не сдержавшись, внезапно разразиться смехом, с характерным призвуком, словно брызгая» появляется в первой половине XIX в., как показывает анализ контекстов из НКРЯ, например: Однажды, отправляясь в Павловск и надевая свою ленту, он посмотрел на меня наискось и не мог удержаться от смеха. $Я$ прыснул, и мы оба расхохотались (А. С. Пушкин. Карамзин. 1821-1825). Лексемы прикол, прикальваться, стебать, стегать, угарный, угорать и т. д. развивают метафорические значения, описанные выше, в начале XXI в., как видим из примеров: $A$ вдруг он инвалид или Квазимодо какое, а мы тут его стебём (Женщина + мужчина: Психология любви (форум). 2004); Вот приколются коллеги с утра: сидит посреди сплошь окровавленного офиса Аплетаев, в руках нога шефа (Александр Гаррос, Алексей Евдокимов. Головоломка. 2001). В русском семантическом поле «Смех» обнаруживается тенденция появления метафорических лексико-семантических вариантов слов из разговорно-просторечной среды.

Наряду со словами и лексико-семантическими вариантами, которые появились в языке сравнительно недавно и появляются постоянно, в нем существует большое количество слов, вышедших или постепенно выходящих из употребления.

Далее рассмотрим слова с семантикой смеха, потерявшие актуальность для русского социума на современном этапе развития языка. Большее количество таких лексических единиц входит в состав ЛСГ существительных - наименований субъектов, вызывающих смех своими действиями: хохмач, смехун, ёрник, шут, иутиха, гаер, паяи, фигляр, скоморох, петрушка, буффон и др. Обратимся к данным ТСО и БТС: 
Смехун (разг.) - тот, кто много или охотно смеется.

Ёрник (устар.) - тот, кто насмехается над кем-либо, чем-либо.

Хохмач (прост.) - шутник, весельчак, острослов.

Буффон - актер, играющий комические, шутовские роли; шут, паяц [1].

Шут - 1. В старину: лицо при барском доме или при дворце, развлекавшее забавными выходками господ и гостей. 2. Комический персонаж в балаганных представлениях, паяц. 3. перен. Тот, кто балагурит на потеху другим, является общим посмешищем. Разыгрывать шута. Шут гороховый - о том, кто выставляет себя в смешном или глупом виде. 4. (nрост.) Употребляется вместо черт в некоторых выражениях. Шут с ним.

Гаер - в старину: балаганный шут.

Паяц - 1. (устар.) Клоун в цирке, балаганный шут. 2. перен. (неодобр.) О человеке, который паясничает.

Фигляр - 1. (устар.) Фокусник, акробат. Ярмарочный ф. 2. перен. (разг., неодобр.) О человеке, который стремится расположить к себе кривляньем, шутовскими выходками.

Арлекин - традиционный персонаж итальянской «комедии масок»; паяц, шут.

Скоморох - 1. В Древней Руси: певецмузыкант, бродячий комедиант. 2. перен. (разг. неодобр.) Несерьезный человек, потешающий других своими шутовскими выходками.

Петрушка - 1. Кукла, главное комическое действующее лицо в народном русском кукольном представлении. 2. (прост., шутл.). Нечто нелепое, странное, смешное [7].

Если слова смехун, хохмач, ёрник становятся все менее употребимыми в связи с тем, что в речи используется их современный синоним шутник, то слова шут, шутиха, гаер, фигляр, скоморох, петрушка, буффон и др. становятся неактуальными для носителя языка по другой причине. Данные лексемы - это наименования людей по роду занятий, которые призваны смешить других, а также названия комических персонажей народного театра. Они описывают пласт русской смеховой культуры Средневековья - культуры шутовства. Как отмечал Д. С. Лихачёв, «одной из самых характерных особенностей средневекового смеха является его направленность на самого смеющегося. Смеющийся чаще всего смеется над самим собой, над своими злоключениями и неудачами. Смеясь, он изображает себя неудачником, дураком. Смеющийся валяет дурака, паясничает, играет, переодевается (вывертывая одежду, надевая шапку задом наперед), изображая свои несчастья и бедствия. В скрытой и в открытой форме в этом «валянии дурака» присутствует критика существующего мира, разоблачаются существующие социальные отношения, социальная несправедливость» [3]. Вместе с постепенным выходом из употребления указанных выше лексем уходит и определенный пласт смеховой культуры. В современном мире на смену шутам, буффонам, петрушкам, паяцам и др. пришли юмористы, комики, сатирики, кавээнщики, резиденты «Камеди Клаба» и др., также призванные смешить людей. Таким образом, происходит частичная смена смеховой парадигмы.

Многие устаревшие лексемы, входящие в ЛСГ существительных - наименований лиц по профессии, продолжают функционировать в речи чаще всего в переносном значении, например: Ax, шуm гороховый! И вот, благодаря природной своей глупости, Федька делается знаменитостью; острота его ходит по рукам, молодых поощряет, стариев умиляет u ymeшает (М. Е. Салтыков-Щедрин. Наша общественная жизнь); В прокат выходит «Бабник» - попьтка Эштона Кутчера дока- 
зать зрителям, что он давно уже не иут гороховый из тинейджерских комедий и шоу MTV, а серьезный драматический актер (Рада Тишина. Плейбой сдался без боя // РБК Daily, 2009.08.10); Хватит строить из себя uyma! (разг. речь). Как видим из последнего примера, обнаруживаются негативные коннотации в употреблении слова шуm в метафорическом значении, что говорит об отрицательном отношении к тем, кто кривляется на потеху другим. Семантика шутовства, которая включала возможность сказать неприятную правду под видом шутки, в метафоре не актуализирована.

Таким образом, семантическое поле «Смех» видится нам как самоорганизующийся динамический фрагмент лексической системы языка, пребывающий в постоянном движении и развитии. С одной стороны, по- являются новые лексические единицы (например, петросянить, смайлик, ЛОЛ) или новые значения слов (например, прикол в значении «шутка», стегать в значении «высмеивать»). С другой стороны, происходит потеря актуальности слов для носителей языка и выход их из употребления (например, буффон, шутиха, смехун, гаер и др.). Динамические процессы в семантическом поле «Смех» отражают и изменения в русской языковой картине мира: вместе с уходом «шутовской» лексики уходит и определенный пласт смеховой культуры. На смену шутам, буффонам, петрушкам, паяцам и др. пришли юмористы, комики, сатирики, кавээнщики, резиденты «Камеди Клаба» и др., также призванные смешить людей - происходит смена смеховой парадигмы.

\section{СПИСОК ЛИТЕРАТУРЫ}

1. Большой толковый словарь русского языка / сост. и гл. ред. С. А. Кузнецов. - СПб.: Норинт, 2000. - $1536 \mathrm{c}$.

2. Караулов Ю. Н. Общая и русская идеография. - М.: Наука, 1976. - 356 с.

3. Лихачев Д. С. Смех в Древней Руси // Избранные работы в 3 т. - Л.: Художественная литература. Ленинградское отделение, 1987. - Т. 2. - 493 с.

4. Маслов Ю. С. Введение в языкознание. - М.: Высшая школа, 1987. -272 с.

5. Ожегов С. И. Лексикология. Лексикография. Культура речи. - М.: Высшая школа, 1974. $-352 \mathrm{c}$.

6. Ожегов С. И. Словарь русского языка: Ок. 53000 слов / под общ. ред. проф. Л. И. Скворцова. - 24-е изд., испр. - М.: Оникс, 2010. - 1200 с.

7. Ожегов С. И. Толковый словарь русского языка Ок. 100000 слов, терминов и фразеологических выражений / под ред. проф. Л. И. Скворцова. - 27-е изд., испр. - М.: Мир и Образование, 2013. - 736 с.

8. Попова С. А. Ментальная структура «Смех» в русской языковой картине мира // Молодая филология - 2013 (I) (по материалам исследований молодых ученых): межвузовский сборник научных трудов. - Новосибирск: Изд. НГПУ, 2013. - Ч. 1. - С. 66-70.

9. Словарь русского языка XI-XVII веков / под ред. Г. А. Богатовой. - М.: Наука, 1995. Вып. 21. - 282 c.

10. Словарь русского языка XI-XVII веков / под ред. Г. А. Богатовой. - М.: Наука, 1997. Вып. 22. - 299 с.

11. Толковый словарь русского языка / под ред. Д. Н. Ушакова. - М.: Астрель, 2004. $1280 \mathrm{c}$. 
Popova Svetlana Andreevna, Post-graduate Student of the Department of the Modern Russian Language, Novosibirsk State Pedagogical University, Novosibirsk, Russian Federation. E-mail: spspsp@list.ru

\title{
DYNAMIC PROCESSES IN THE SEMANTIC FIELD “LAUGH”
}

\author{
(IN THE RUSSIAN LANGUAGE)
}

\begin{abstract}
The article describes the dynamic processes, happening in the semantic field "Laugh". It consists of lexico-semantic groups of verbs, nouns, adjectives, adverbs, words of a category of state and interjections. The author considers the changes of the lexical structure of the lexico-semantic groups of verbs, verbal idioms and nouns, entering this semantic field. Special attention is paid to the emergence of new words and new lexical meanings, and also a release of words from the use. At the end of the article the author sums it all up by saying, that the semantic field "Laugh" is a selforganizing dynamic fragment of the Russian lexical system. It constantly changes and develops. On the one hand, dynamic processes in the semantic field "Laugh" show changes of life of the Russian society, but on the other hand, changes in the Russian language picture of the world are reflected in them. A release of words from the use shows changes of a condition of the Russian laughter culture.

\section{Keywords}

dynamic processes, semantic field, lexico-semantic group, lexical meaning, seme, component analysis.

\section{REFERENCES}

1. Big explanatory dictionary of Russian (ed.) S. A. Kuznetsov. St. Petersburg: Norint Publ., 2009. 1536 p. (In Russian)

2. Karaulov Yu. N. General and Russian ideography. Moscow: Nauka Publ., 1976. 356 p. (In Russian)

3. Likhachev D. S. The laugh in the Ancient Russia. Elite of work in 3 vol. Leningrad: Art Literature Publ., 1984. 493 p. Vol. 2. (In Russian)

4. Maslov Yu. S. An introduction to linguistics. Moscow: The higher School Publ., 1987. 272 p. (In Russian)

5. Ozhegov S. I. Leksikologiya. Lexicography. Standard of speech. Moscow: The Higher school, 1974. 352 p. (In Russian)

6. Ozhegov S. I. Explanatory dictionary of Russian. (Ed.) L. I. Skvortsov. Moscow: Onyx Publ., 2010. 1200 p. (In Russian)

7. Ozhegov S. I. Explanatory dictionary of Russian. (Ed.) L. I. Skvortsov. Moscow: World and Education Publ., 2013. 736 p. (In Russian)

8. Popova S. A. The mental structure "Laughter" in the Russian picture of the world. Young philology - 2013 (on materials of researches of young scientists): interuniversity collection of scientific works. Novosibirsk: NSPU Publ., 2013. Rt. 1, pp. 66-70. (In Russian)
\end{abstract}


9. The dictionary of Russian of the XI-XVII centuries (Ed.) G. A. Bogatova. Moscow: Nauka Publ., 1995. 282 p., vol. 21. (In Russian)

10. The dictionary of Russian of the XI-XVII centuries (Ed.) G. A. Bogatova. Moscow: Nauka Publ., 1997. 299 p., Vol. 22. (In Russian)

11. The explanatory dictionary of Russian (Ed.) D. N. Ushakov. Moscow: Astrel Publ., 2004. 1280 p. (In Russian) 